\title{
Rescue percutaneous coronary recanalization of right coronary artery by retrograde approach
}

\author{
Leszek Bryniarski', Tomasz Kameczura' ${ }^{1}$, Sławomir Surowiec ${ }^{1}$, Dariusz Dudek ${ }^{2}$, Danuta Czarnecka ${ }^{1}$ \\ ${ }_{1}^{1} 1^{\text {st }}$ Department of Cardiology and Hypertension, Jagiellonian University Medical College, Krakow, Poland \\ 2Department of Interventional Cardiology, Jagiellonian University Medical College, Krakow, Poland
}

Postep Kardiol Inter 2013; 9, 2 (32): 172-175

DOI: $10.5114 /$ pwki.2013.35454

\begin{abstract}
We describe the case of a 62-year-old female patient in whom there was an occlusion of collaterals and acute inferior wall ischemia during the opening procedure of right coronary artery (RCA) chronic total occlusion. Rescue percutaneous coronary intervention (PCI) of RCA by the retrograde approach was performed preventing heart muscle damage. In this article we discuss the issue of PCI by the retrograde technique.
\end{abstract}

Key words: chronic total occlusion, retrograde approach, myocardial infarction.

\section{Introduction}

Percutaneous coronary intervention $(\mathrm{PCI})$ is the primary method of treatment of significant coronary atherosclerosis. Recently, thanks to technological advances and increasing experience of the operators, we have observed the overcoming of the last barrier, which is the recanalization of chronic total occlusions (CTO). Chronic total occlusions is defined as a lack of flow in the analyzed artery segment (TIMI 0), which lasts more than 3 months [1, 2]. Numerous studies have demonstrated a beneficial effect of recanalization on angina symptoms and left ventricular function. The presence of chronic occlusion increases the risk of death three times in case of acute coronary syndrome occurrence [3].

\section{Case report}

A 62-year-old woman, a tobacco smoker, was admitted to the district cardiology ward in December 2011 for the invasive diagnosis of ischemic heart disease due to exertional angina CCS class II/III present for 5 months and a clinically and electrographically positive result of the exercise test. Electrocardiographic examination showed intermediate heart axis, regular sinus rhythm $66 \mathrm{bmp}$ and $1^{\text {st }}$ degree atrioventricular block (PQ $220 \mathrm{~ms}$ ). Echocardiographic study did not demonstrate regional wall motion abnormalities and the ejection fraction was $68 \%$.
Coronary angiography disclosed chronic occlusion of the right coronary artery (Figure 1) and a concomitant attempt to restore the patency of the vessel was made. The use of a 6 F JR 4.0 SH guiding catheter, the guidewires Choice Floppy (Boston Scientific, USA), Crossit 100 (Abbott Vascular, USA) and PT 2 NS (Boston Scientific, USA), and balloon catheters $(1.0 \mathrm{~mm} \times 5 \mathrm{~mm}$ and $1.5 \mathrm{~mm} \times 12 \mathrm{~mm})$ did not allow the occlusion to be crossed. The procedure was stopped and the patient was sent to the reference center in Krakow for another attempt to restore the patency of the RCA.

A second attempt to open the RCA was made 4 months later in the $1^{\text {st }}$ Department of Cardiology and Hypertension, JUMC in Krakow. The occlusion was visualized in detail via right and left femoral artery access ( $7 \mathrm{~F}$ sheaths). At the beginning an antegrade technique was used. Initially, the Asahi Fielder XT (Asahi Intecc, Japan) guidewire followed by the Asahi Miracle Bros 3 (Asahi Intecc, Japan) guidewire with an over-the-wire (OTW) balloon were applied. During an attempt to cross the occlusion with a guidewire a dissection in the proximal part of the artery occurred leading to complete cessation of flow through the ipsilateral circulation (Figures 2 and 3).

The patient reported chest pain and ECG demonstrated ST-segment elevation (Pardee wave) in the inferior wall leads. Because of the favorable anatomy of the anatomical connection between the septal branches and the dis- 
tal RCA segment (Figure 4) it was decided to immediately switch to a retrograde method of RCA recanalization. The Asahi Fielder XT $300 \mathrm{~cm}$ guidewire (Asahi Intecc, Japan) and the microcatheter Corsair (Asahi Intecc, Japan) were introduced through the first perforator into the distal RCA segment. The same guidewire was used for retrograde opening of the artery. The guidewire and subsequently also the Corsair microcatheter were introduced into the guiding catheter (Figure 5). In the next step the Fielder XT guidewire was exchanged for the externalization Asahi RG3 guidewire (Asahi Intecc, Japan). The patient's condition improved, and she reported reduction of chest pain. After externalization of the RG3 guidewire the procedure was continued using an antegrade technique: the Maverick $1.5 \mathrm{~mm} \times 15 \mathrm{~mm}$ and subsequently $2.0 \mathrm{~mm} \times 20 \mathrm{~mm}$ balloon catheters (Boston Scientific, USA) were inflated several times. This was followed by DES implantation - $3.0 \mathrm{~mm} \times 38 \mathrm{~mm}$ Endeavour Resolute (Medtronic, USA) under the pressure of $12 \mathrm{~atm}$ (Figure 6), which led to an optimal result (lack of residual stenosis, TIMI 3 flow) (Figure 7). The procedure lasted $85 \mathrm{~min}$, the radiation dose was $2.54 \mathrm{~Gy}$, the exposure time was $34.5 \mathrm{~min}$, and $550 \mathrm{ml}$ of the Ultravist 370 contrast agent (Bayer, Germany) was administered. Marker enzymes after the procedure were negative. The patient is in good condition and does not report any symptoms 12 months after the procedure.

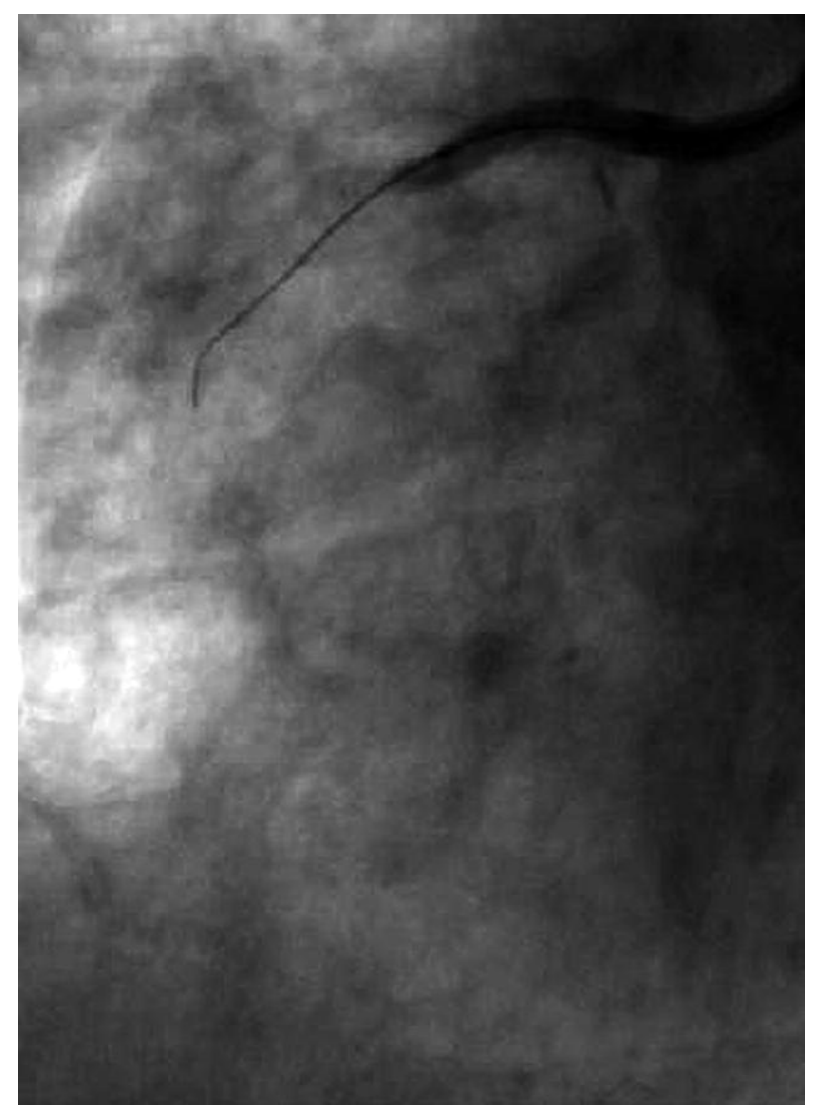

Fig. 2. Dissection in proximal part of right coronary artery totally occluding collaterals (TIMI 0)

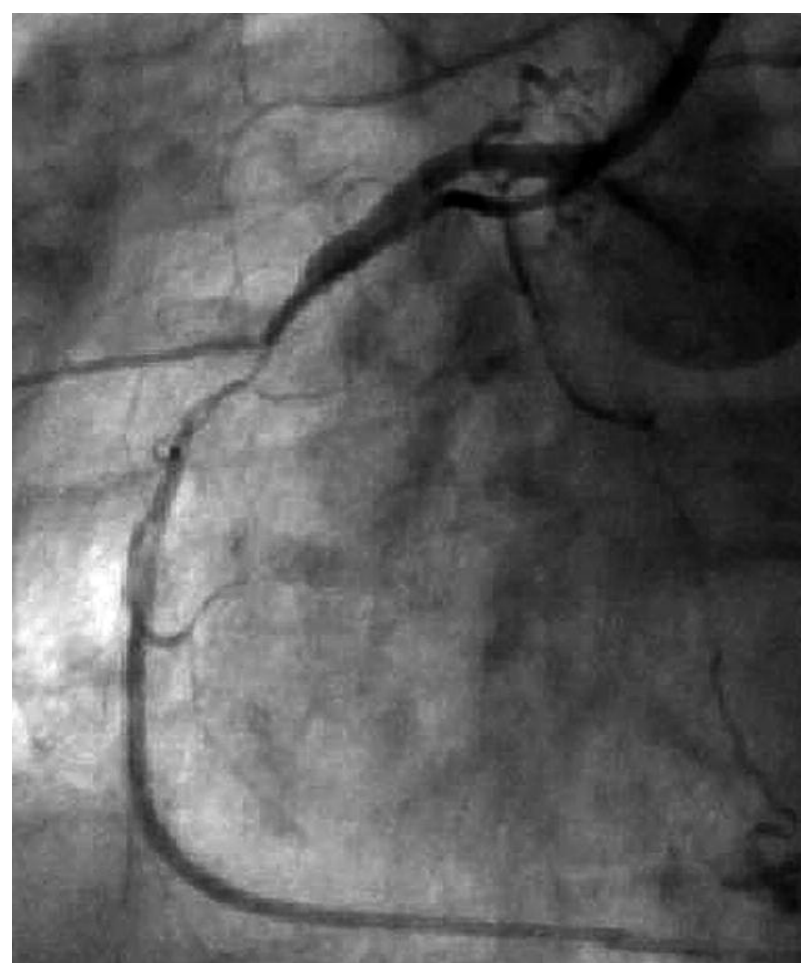

Fig. 1. Right coronary artery chronic total occlusion located in proximal part, length approximately $20 \mathrm{~mm}$

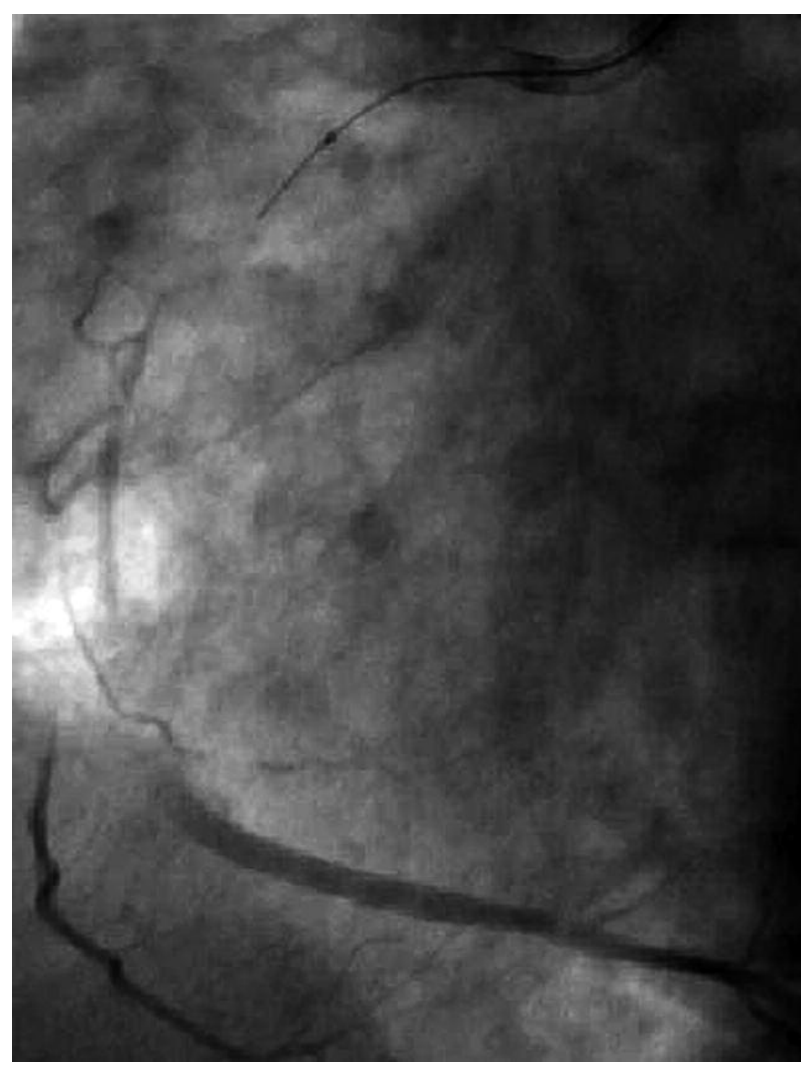

Fig. 3. Contralateral contrast media injection to left coronary artery makes visible distal part of RCA (Rentrop scale 2, Werner scale 2) 


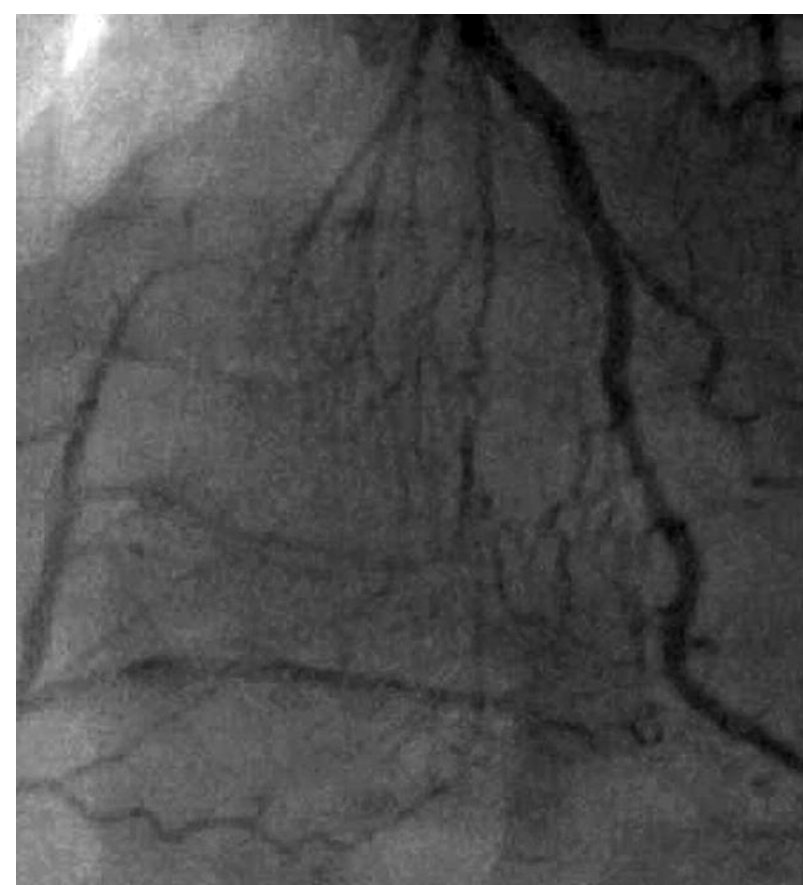

Fig. 4. Contrast media injection to left coronary artery makes visible connections with distal part of RCA through septal vessels

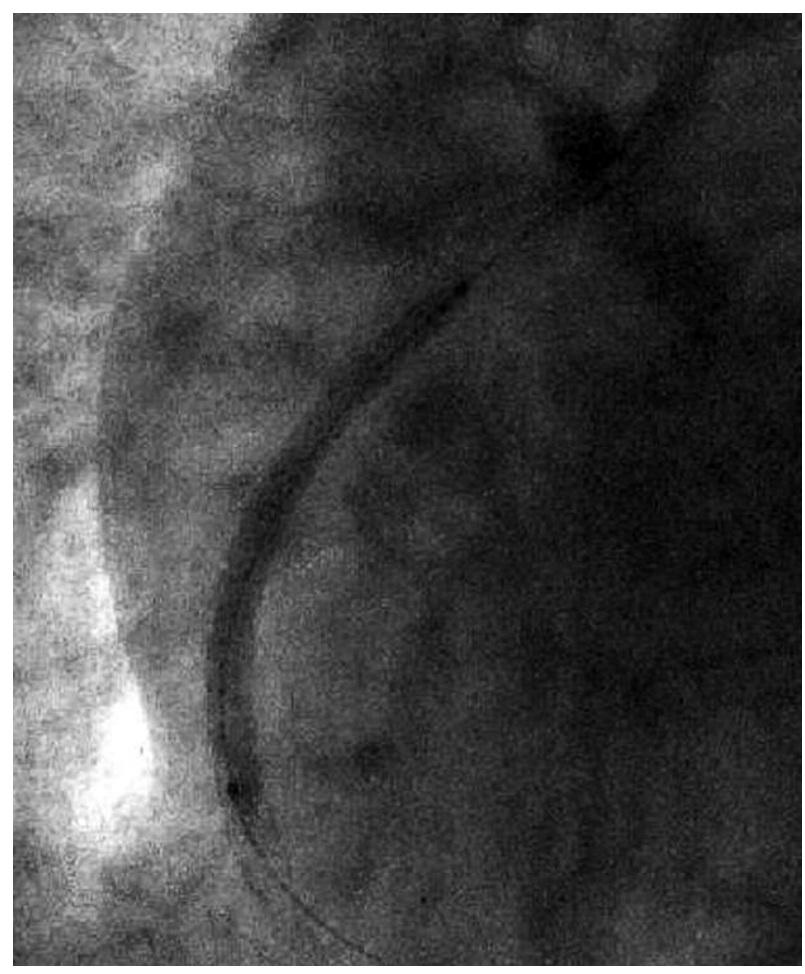

Fig. 6. Inflation of drug-eluting stent Resolute Endeavour

\section{Discussion}

Many studies have shown a beneficial effect of recanalization of chronic total occlusions (СTO) on patient's survival and prognosis. Successful recanalization proce-

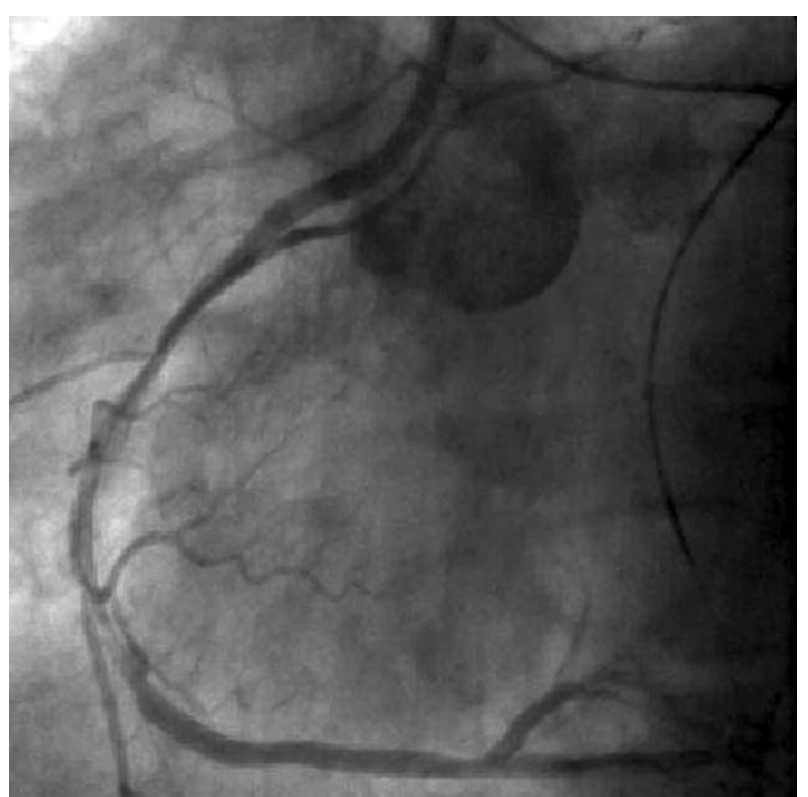

Fig. 5. Coronary guidewire Asahi Fielder XT 300 performed by retrograde method through occlusion. Also visible is the Corsair microcatheter entered into RCA

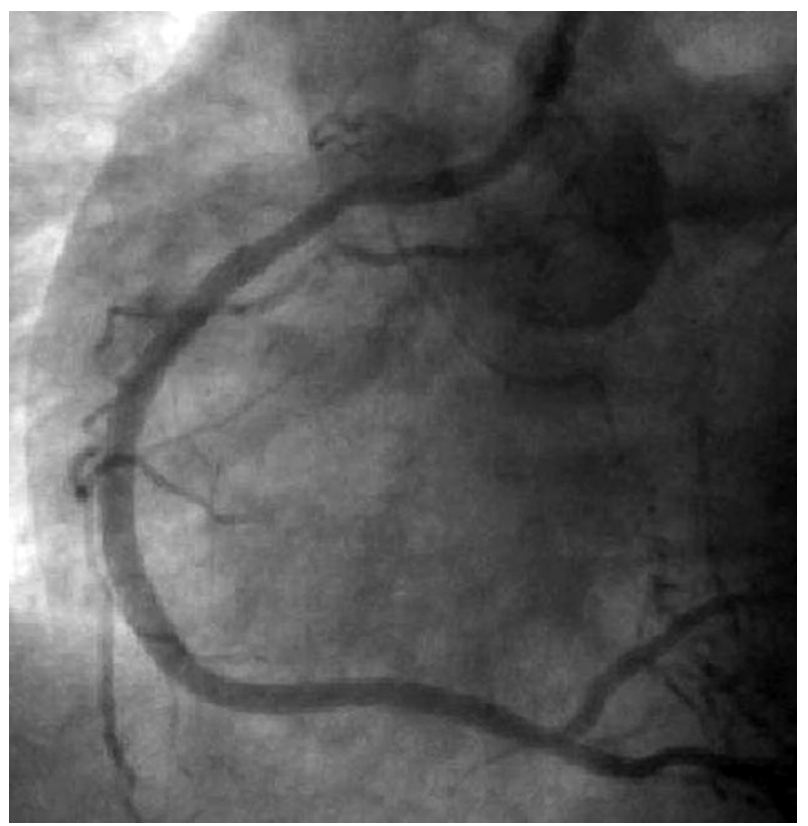

Fig. 7. Optimal effect of right coronary artery $\mathrm{PCl}$ with DES implantation

dures improve the patient's clinical condition, exercise capacity assessed by exercise testing and left ventricle ejection fraction $[4,5]$. Despite the obvious benefits, according to EuroCTO Club data from 2007, an attempt to restore patency was made only in $12 \%$ of patients with confirmed presence of chronic occlusion [6]. The reason for this, among others, is the fact that the procedures of CTO recanaliza- 
tion are harder, longer and require specific skills and dedicated equipment.

The development of technique (new generation of guidewires, microcatheters) allowed the introduction of a retrograde method into clinical practice in 1990, which further improved the effectiveness of the procedure. The described technique of crossing with a guidewire through the occlusion, antegrade balloon predilation and antegrade stent introduction/implantation is known as pure retrograde crossing technique. There also other techniques of CTO recanalization such as controlled antegrade retrograde subintimal tracking (CART) [7], reverse CART, knuckle technique and marker wire technique. Which of these methods the operator will use depends on his experience and individual anatomical conditions of the patient [8]. Limitations of the method may include high radiation dose and the amount of contrast agent as well as specific complications. It is also necessary to have all equipment. The guidewire used for the retrograde method (the Asahi Fielder XT 300) is hydrophilic and coated with polymer. It is dedicated to procedures on tortuous coronary arteries, subtotal stenosis and chronic total occlusions treated with the use of a sliding technique and retrograde approach. The guidewire has a spherical tip on the 0.009 " diameter core and a pressure force of $1.2 \mathrm{~g}$, which allows easy penetration of microchannels with relatively low risk of vessel perforation. The Corsair microcatheter used to cross the septal branches is a special catheter made of a weave of 10 steel strands (called SHINKA-Shaft) with diameters of $0.07 \mathrm{~mm}$ and $0.12 \mathrm{~mm}$, and provides flexibility while maintaining a relatively high pushing force. In addition, the microcatheter enables the exchange of a guidewire and administration of contrast agent directly into the collaterals. The last $5 \mathrm{~mm}$ of the microcatheter are covered with tungsten and easily penetrate into the microcirculation. The Asahi RG3 guidewire was also used during the procedure. It is designed for retrograde procedures, it allows externalization and is covered with a hydrophilic coat (SLIP technology COAT) for easy maneuvering even in vessels with high tortuosity. Its length $(330 \mathrm{~cm})$ and small diameter $(0.26 \mathrm{~mm})$ while retaining rigidity facilitate the externalization of the guidewire and switching from a retrograde to an antegrade method. The initial section of the RG3 guidewire is an $8 \mathrm{~cm}$ coil in the form a regular screw increasing penetration capabilities, as well as reducing the incidence of perforation.

There are very few similar cases described in the literature. They are mainly related to the rescue retrograde method as a treatment of iatrogenic long spiral dissections occurring as a complication of the antegrade method (in case of the appropriate anatomy of the ipsilateral circulation) [8]. The most common complications of the retrograde method include dissection and perforation of the collaterals $(2.1 \%$ and $1.7 \%$, respectively) and occlusion of the artery, which was used for retrograde introduction of the guidewire (1.1\%) [9]

Clinical evidence clearly supports the role of chronic total occlusion recanalization in the reduction of the patient's cardiovascular risk. Due to the need of the relevant experience currently there are only a few centers in Poland using the retrograde technique. This is consistent with the guidelines of the EuroCTO Club recommending creation of reference centers and training of operators dedicated to this procedure.

\section{References}

1. Stone GW, Kandzari DE, Mehran R, et al. Percutaneous recanalization of chronically occluded coronary arteries: a consensus document: part I. Circulation 2005; 112: 2364-2372.

2. Sianos G, Werner GS, Galassi AR, et al. EuroCTO Club. Recanalisation of chronic total coronary occlusions: 2012 consensus document from the EuroCTO club. Eurolntervention 2012; 8: 139-145.

3. van der Schaaf RJ, Vis MM, Sjauw KD, et al. Impact of multivessel coronary disease on long-term mortality in patients with ST-elevation myocardial infarction is due to the presence of a chronic total occlusion. Am J Cardiol 2006; 98: 1165-1169.

4. Borgia F, Viceconte N, Ali O, et al. Improved cardiac survival, freedom from mace and angina-related quality of life after successful percutaneous recanalization of coronary artery chronic total occlusions. Int J Cardiol 2011; 161: 31-38.

5. Melchior JP, Doriot PA, Chatelain P, et al. Improvement of left ventricular contraction and relaxation synchronism after recanalization of chronic total coronary occlusion by angioplasty. J Am Coll Cardiol 1987; 9: 763-768

6. Di Mario C, Werner GS, Sianos G, et al. European perspective in the recanalisation of chronic total occlusions (CTO): consensus document from the EuroCTO Club. Eurolntervention 2007; 3: 30-43.

7. Surmely JF, Tsuchikane E, Katoh O, et al. New concept for CTO recanalization using controlled antegrade and retrograde subintimal tracking: the CART technique. J Invasive Cardiol 2006; 18: 334-338.

8. Sianos G, Barlis P, Di Mario C, et al. European experience with retrograde approach for the recanalisation of coronary artery chronic total occlusions. A report on behalf of the EuroCTO club. Eurointervention 2008; 4: 84-92.

9. Muramatsu T, Tsukahara R, Ito $Y$, et al. Changing strategies of the retrograde approach for chronic total occlusion during past the 7 years. Catheter Cardiovasc Interv 2013; 81: E178-E185. 